\title{
The Relationship between Phosphate Adsorption and Soil Organic Carbon from Organic Matter Addition
}

\author{
Fadly Hairannoor Yusran ${ }^{1}$ \\ Received 12 May 2009/accepted 30 November 2009
}

\begin{abstract}
The Relationship between Phosphate Adsorption and Soil Organic Carbon from Organic Matter Addition (FH Yusran): The application of organic matter (OM) can increase soil phosphorus (P) availability via soil mineralisation. In lateritic soils, however, soluble organic carbon (OC) from OM may also reduce phosphate adsorption capacity, a process that also releases $\mathrm{P}$ in soil solution. In these soils, competitive adsorption could be dominant compared to mineralisation. The main objectives of this study were to study phosphate adsorption in three lateritic soils which have been treated with different types and amounts of organic amendment, and had intrinsic OC removed by combustion. The adsorption isotherms showed that OM addition could reduce phosphate adsorption and that this reduction could last up to nine months after application. Lucerne hay was more effective than peat and wheat straw additions in reducing phosphate adsorption capacity. The bicarbonate phosphorus (BP) release through mineralisation occurred despite the increase of phosphate adsorption capacity due to the combustion of soil samples. Peat treatment was predicted to be more effective in creating organo-metal complexes with $\mathrm{Al}$ and Fe. Overall, mineralisation from added organic amendment was effective in minimising P adsorption in lateritic soil.
\end{abstract}

Keywords: Lateritic soils, phosphate adsorption, soil organic carbon

\section{INTRODUCTION}

The addition of OM to soils may increase phosphate availability by decomposition and mineralisation of organic-P (OP), or by abiotic processes such as ligand-exchange effects on phosphate adsorption. It is difficult to separate the effects of biotic and abiotic processes on the release of phosphate. This article describes experimental work which investigated the direct effect of OM addition on adsorption of phosphate in four types of lateritic soils.

The OM content of highly weathered soils has been shown to be negatively correlated with phosphate adsorption capacity. For example, Singh and Gilkes (1991) found a negative correlation between phosphate sorption by soil (quantified by the Freundlich $K_{F}$ parameter) and soil OM (SOM) content for 97 mainly highly weathered soils of Western Australia. Based on Freundlich $K_{F}$ values, Dubus and Bacquer (2001) also found a significant negative correlation between phosphate sorption and SOM content.

Three abiotic mechanisms are proposed to explain the role of SOM increase $\mathrm{P}$ availability in soils (Iyamuremye and Dick 1996). First, soluble organic molecules may specifically adsorb to soil minerals by ligand exchange in competition with phosphate (Erich et al. 2002; Ohno and Crannel 1996; Singh and Jones 1976). Second, the soluble OM may react with bound $\mathrm{Al}^{3+}$ or $\mathrm{Fe}^{3+}$ at the surface of mineral phase to form soluble complexes of these elements and release phosphate which was previously sorbed or which was present as insoluble $\mathrm{Al}$ and $\mathrm{Fe}$-phosphate (Haynes and Mokolobate 2001). Third, OM may be sorbed to soil particles at non-specific sorption sites, resulted in higher negative charge of the particles (Haynes and Naidu 1998; Naidu et al. 1997). This process reduces the electrostatic attraction of phosphate and decreases phosphate ions activity at the reactive surface. All three abiotic mechanisms may occur simultaneously, and in combination with biotic release of phosphate by mineralisation.

${ }^{1}$ Soil Department, Faculty of Agriculture, Lambung Mangkurat University, Banjarbaru 70714

Email: fhyusran@unlam.ac.id

J Trop Soils, Vol. 15, No. 1, 2010: 1-10

ISSN 0852-257X 


\section{FH Yusran: Organic Matter Addition on Phosphate Adsorption and Soil Organic Carbon}

Results from previous experiments (Yusran et al. 2005; Yusran 2008) showed that phosphate, extracted with $0.5 \mathrm{M} \mathrm{NaHCO}_{3} \mathrm{pH} 8.5$ (BP), was significantly higher in soil amended with OM than in unamended soil, especially from green manure amendment (lucerne hay) followed by peat. The effect of soluble OM on phosphate release from Oxisols has been found to be transient (Afif et al. 1995). The findings in this work therefore lead to the question of whether peat (the passive pool) would have a longer abiotic effect due to its resistance to decomposition, and possible slow release of soluble organic ligands which can compete for adsorption sites with phosphate. This issue is poorly understood. The abiotic effects of $\mathrm{OM}$ additions could be determined by analysing phosphate adsorption isotherms for soil incubated with lucerne hay and peat for varying lengths of time up to one year. Organic matter addition also released $\mathrm{P}$ to the soil solution as a result of biotic mineralisation process (Cobo et al. 2002; Kwabiah et al. 2003; Lupwayi et al. 2003). These two mechanisms maybe particularly difficult to separate in soils with high sorbing capacity for phosphate, such as lateritic soils with high sesquioxide or 1:1 clay content. By (i) observing net release of extractable phosphate (Yusran 2008) and (ii) determining phosphate adsorption isotherm, the two processes (inorganic effects on adsorption, and mineralisation of OP) can be separated as being more and less important for releasing soluble phosphate into soils.

In summary, it is expected that OM addition will reduce phosphate adsorption in soils, and this hypothesis will be addressed by determining phosphate adsorption at a range of OM application rates. This work will also test the novel hypotheses that: (i) any reduction in phosphate adsorption will be temporarily depending on the persistence of $\mathrm{OM}$ added (for example, peat is expected to reduce phosphate adsorption for longer than lucerne hay), and (ii) newly added OM will decrease phosphate adsorption, in the short-term, more than pre-existing SOM.

The objectives of this experiment were therefore: (i) to determine the effect of OM application rate on phosphate adsorption to soil, (ii) to determine the interactive effect of (a) application of different types of $\mathrm{OM}$ (varying in persistence following application) and (b) organic amendment-soil incubation time on phosphate adsorption to soil, (iii) to determine the effect of pre-existing SOM and newly added organic amendments on $\mathrm{PO}_{4}-\mathrm{P}$ adsorption in soils, (iv) to study the effect of phosphate adsorption and $\mathrm{P}$ mineralisation after OM addition on the process of bicarbonate-P release; and (v) to study the changes in dissolved organic-C (DOC) after OM treatment on closely related factors of phosphate adsorption in soil, e.g. $\mathrm{Al}, \mathrm{Fe}$, and $\mathrm{pH}$.

\section{MATERIALS AND METHODS}

\section{Design of the Experiment}

Soil samples for the experiments were from four lateritic soils (two Oxisols, an Ultisol, and a deep regolith material or subsurface soil). The experiments were divided into three subsets which had been subjected to the following treatments: (i) soil incubation with peat, wheat straw, and lucerne hay treatment at $80 \mathrm{Mg} \mathrm{ha}^{-1}$ for different times $(3,6,9$, and 12 months), (ii) different OM levels (40, 80, 120, and $160 \mathrm{Mg} \mathrm{ha}^{-1}$ ) for peat, wheat straw, and lucerne hay, incubated with soil for six months, (iii) type of SOM (existing and new). The existing refers to inherent SOM plus additional fresh $\mathrm{OM}$ as of point 1. Whilst new refers to equal (in $\mathrm{OC}$ concentration) replacement of SOM plus additional fresh OM.

The first subset of this experiment was in a factorial design experiment with two factors: incubation time (3, 6, 9, and 12 months), and source of OM (nil (control), peat, wheat straw, and lucerne hay). The second subset was also factorial with two factors: source of OM (nil (control), peat, wheat straw, and lucerne hay), and OM levels (40, 80, 120, and $160 \mathrm{Mg}$ ha ${ }^{1}$ ). The third subset was a factorial design with three factors: soils (an Ultisol, an Oxisol, and a subsurface soil), type of SOM (existing and new), and OM source (peat and lucerne hay).

The preparation for the first and the second subset of the experiment samplings and related data are described in Yusran (2008). Statistical analyses were performed either with GenStat (Payne et al. 1987) for analyses of variance, or SPSS (Coakes 2001) for regression analyses.

Phosphate adsorption isotherm was measured using methods of Morel et al. (1996) and Erich et al. (2002). Two common adsorption isotherm equations, Langmuir and Freundlich, were used to fit the phosphate adsorption data. The Langmuir equation, which is normally written as (Barrow 1978):

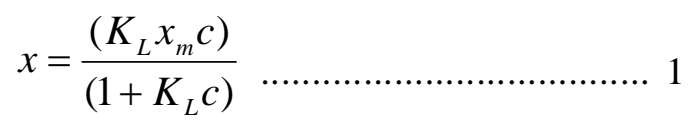


becomes a linear equation when rearranged:

$$
\frac{c}{x}=\frac{1}{K_{L} x_{m}}+\frac{1}{x_{m}} c
$$

where $c=$ concentration of $\mathrm{P}$ in equilibrium solution (mg P mL $\left.{ }^{-1}\right), x=$ amount of $\mathrm{P}$ sorbed ( $\mathrm{mg} \mathrm{P} \mathrm{g}^{-1}$ soil), $x_{m}=$ sorption maximum ( $\mathrm{mg} \mathrm{P} \mathrm{g}^{-1}$ soil), and $K_{L}=$ coefficient related to bonding energy. A plot of $c / x$ versus $c$ therefore has a slope of $1 / x_{m}$ and intercept of $1 / K_{L} \cdot x_{m}$.

The Freundlich equation, which is normally written as (Barrow 1978):

$$
x=K_{F} c^{b}
$$

can be log-transformed to give simple linear equations:

$$
\log x=\log K_{F}+b \log c
$$

where $c=\mathrm{P}$ concentration in equilibrium solution ( $\mathrm{g} \mathrm{P}$ $\left.\mathrm{mL}^{-1}\right), x=$ amount of $\mathrm{P}$ sorbed ( $\mathrm{mg} \mathrm{P} \mathrm{g}^{-1}$ soil), $K_{F}$ and $b=$ constants with $K_{F}$ being a a measure of adsorption surface and $b$ relating to the energy of adsorption (Barrow 1978). A plot of $\log x$ versus $\log c$ has a slope $b$ and intercept $\log K_{F}$.

Due to their simplicity, i.e. only two adjustable parameters, the Langmuir and Freundlich equations do not always fit experimental data well. The Brunauer-Emmett-Teller (BET) equation was applied to take into account the plateaus, points of inflection, and maxima observed in some data (Giles et al. 1974; Hinz 2001). Unlike the Langmuir and Freundlich equations, which are classified as high affinity adsorption equations, the BET is an adsorption equation that can explain sigmoidal isotherms, as observed for some data from this experiment.

The equation is usually written (Burau and Zasoski 2002):

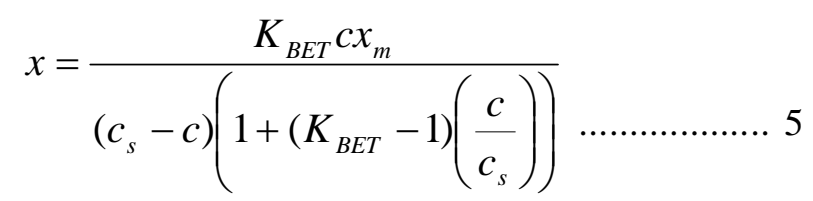

Like the other two equations, the BET equation has a linear form after algebraic rearrangement:

$$
\frac{c}{c_{s}-c} \cdot \frac{1}{x}=\frac{1}{K_{B E T} x_{m}}+\left(\frac{\left(K_{B E T}-1\right)}{K_{B E T} x_{m}}\right)\left(\frac{c}{c_{s}}\right) \ldots \ldots 6
$$

where $c=\mathrm{P}$ concentration in equilibrium solution ( $\mathrm{g} \mathrm{P}$ $\left.\mathrm{mL}^{-1}\right), c_{s}=$ the concentration of the solute (i.e. soil), $x_{m}=\operatorname{adsorption}$ maximum $\left(\mathrm{mg} \mathrm{P} \mathrm{g}^{-1}\right.$ soil), and $K_{B E T}=$ a constant for energy of interaction with soil particles (Burau and Zasoski 2002). A plot of $c /\left(c_{s}-c\right)(1 / x)$ versus $c /\left(c_{s}-c\right)$ therefore has a slope $\left(K_{B E T} 1\right) /\left(K_{B E T} x_{m}\right)$ and intercept $1 /\left(K_{B E T} x_{m}\right)$.

\section{Statistical Analysis}

In order to determine the statistical significance of differences between treatments, linear regression analysis with grouped data was performed on data transformed to give linear Langmuir or Freundlich relationships, as described above. This procedure allowed statistical significance to be assessed without replication of points on adsorption isotherms.

\section{RESULTS AND DISCUSSION}

Based on the values of adsorption isotherm parameters for the Langmuir and Freundlich equations (Table 1 and Table 2), the data presented support the hypothesis that organic amendments decreased the soils' affinity (Langmuir $K_{L}$ ) and capacity (Freundlich $K_{F}$ ) for phosphate adsorption. These results are in agreement with Iyamuremye et al. (1996) and Hue et al. (1994) that addition of organic amendments can significantly decrease phosphate adsorption capacity of the soil.

Although wheat straw application reduced phosphate adsorption as also observed by Reddy et al. (2001), peat and lucerne hay applications reduced phosphate adsorption for longer (up to nine months after treatments). For peat and lucerne hay applications nine-month incubation was significantly greater $(\mathrm{p} \leq 0.01)$ than the three-month incubation.

Peat persisted longer than lucerne hay in soil (Yusran et al. 2002; Yusran, 2008), but lucerne hay produced more DOC than other sources (i.e. peat and wheat straw) which would be expected to decrease phosphate adsorption (Erich et al. 2002). In addition, the nature of soluble organic matter from peat is likely to be relatively recalcitrant and to have a more longlasting effect in blocking phosphate adsorption sites, whilst the abundant simple organic acids originating from plant materials are easily degradable. It is therefore assumed that peat application decreased phosphate adsorption, at least partly, by mechanism other than competitive ligand exchange with DOC.

The reduction of phosphate adsorption by the organic amendments persisted for at least 12 months following application, shown by the continued difference between treatments and controls (e.g. 
Table 1. The effect of organic matter sources $\left(80 \mathrm{Mg} \mathrm{ha}^{-1}\right)$ and incubation time on phosphate adsorption parameters based on Langmuir and Freundlich equations.

\begin{tabular}{lcccccc}
\hline \multirow{2}{*}{$\begin{array}{c}\text { Organic matter } \\
\text { sources }\end{array}$} & \multicolumn{3}{c}{ Langmuir } & \multicolumn{3}{c}{ Freundlich } \\
\cline { 2 - 7 } & $\mathrm{K}_{\mathrm{L}}$ & $\mathrm{x}_{\mathrm{m}}$ & $\mathrm{R}^{2}$ & $\mathrm{~b}$ & $\mathrm{~K}_{\mathrm{F}}$ & $\mathrm{R}^{2}$ \\
\hline \multicolumn{3}{c}{ Three months } \\
Control & 0.7934 & 1094.1 & 0.997 & 0.41196 & 457.9 & 0.912 \\
Peat & 0.6068 & 1150.8 & 0.993 & 0.44838 & 424.4 & 0.949 \\
Wheat straw & 0.5894 & 1018.3 & 0.997 & 0.37781 & 387.2 & 0.967 \\
Lucerne hay & 0.4343 & 1065.0 & 0.996 & 0.42039 & 347.2 & 0.957 \\
\multicolumn{5}{c}{ Six months } \\
Control & 0.6869 & 1017.3 & 0.994 & 0.36010 & 414.7 & 0.985 \\
Peat & 0.6875 & 1021.5 & 0.996 & 0.36998 & 412.9 & 0.970 \\
Wheat straw & 0.4476 & 979.4 & 0.993 & 0.36612 & 342.1 & 0.990 \\
Lucerne hay & 0.4087 & 940.7 & 0.995 & 0.35026 & 325.5 & 0.991 \\
\multicolumn{7}{c}{ Nine months } \\
Control & 0.5981 & 1035.2 & 0.984 & 0.35554 & 406.5 & 0.912 \\
Peat & 0.4077 & 995.0 & 0.992 & 0.37298 & 338.5 & 0.952 \\
Wheat straw & 0.3761 & 1078.8 & 0.980 & 0.42485 & 331.3 & 0.974 \\
Lucerne hay & 0.2233 & 962.5 & 0.992 & 0.40546 & 246.4 & 0.975 \\
Control & 0.6751 & 1074.1 & 0.995 & 0.40017 & 423.8 & 0.983 \\
Peat & 0.5086 & 1124.9 & 0.994 & 0.44033 & 385.7 & 0.986 \\
Wheat straw & 0.5359 & 1038.4 & 0.996 & 0.39345 & 376.3 & 0.976 \\
Lucerne hay & 0.4524 & 1012.2 & 0.993 & 0.38131 & 349.1 & 0.991 \\
\hline
\end{tabular}

Table 2. The effect of organic matter sources and levels on phosphate adsorption parameters at six months incubations time based on Langmuir and Freundlich equations.

\begin{tabular}{|c|c|c|c|c|c|c|}
\hline \multirow{2}{*}{$\begin{array}{l}\text { Organic matter } \\
\text { sources }\end{array}$} & \multicolumn{3}{|c|}{ Lang muir } & \multicolumn{3}{|c|}{ Freundlich } \\
\hline & $\mathrm{K}_{\mathrm{L}}$ & $\mathrm{X}_{\mathrm{m}}$ & $\mathrm{R}^{2}$ & $\mathrm{~b}$ & $\mathrm{~K}_{\mathrm{F}}$ & $\mathrm{R}^{2}$ \\
\hline \multicolumn{7}{|c|}{$40 \mathrm{Mg} \mathrm{ha}^{-1}$} \\
\hline Control & 0.9764 & 1005.2 & 0.989 & 0.33493 & 467.8 & 0.972 \\
\hline Peat & 0.7811 & 1049.3 & 0.992 & 0.36795 & 445.9 & 0.990 \\
\hline Wheat straw & 0.7513 & 1000.0 & 0.990 & 0.34062 & 426.8 & 0.989 \\
\hline Lucerne hay & 0.6391 & 956.9 & 0.989 & 0.30622 & 402.5 & 0.991 \\
\hline \multicolumn{7}{|c|}{$80 \mathrm{Mgha}^{-1}$} \\
\hline Control & 0.8797 & 1036.3 & 0.987 & 0.35414 & 462.9 & 0.975 \\
\hline Peat & 0.8077 & 1009.1 & 0.991 & 0.34112 & 440.6 & 0.994 \\
\hline Wheat straw & 0.5657 & 956.0 & 0.993 & 0.33173 & 375.9 & 0.995 \\
\hline Lucerne hay & 0.4670 & 967.1 & 0.979 & 0.32035 & 365.5 & 0.959 \\
\hline \multicolumn{7}{|c|}{$120 \mathrm{Mg} \mathrm{ha}^{-1}$} \\
\hline Control & 0.8029 & 1006.0 & 0.993 & 0.33969 & 439.0 & 0.969 \\
\hline Peat & 0.7898 & 1008.1 & 0.991 & 0.34005 & 437.7 & 0.980 \\
\hline Wheat straw & 0.5095 & 967.9 & 0.987 & 0.33328 & 364.4 & 0.988 \\
\hline Lucerne hay & 0.4695 & 922.5 & 0.984 & 0.30698 & 355.6 & 0.984 \\
\hline \multicolumn{7}{|c|}{$160 \mathrm{Mg} \mathrm{ha}^{-1}$} \\
\hline Control & 0.8603 & 1027.8 & 0.993 & 0.35592 & 454.0 & 0.973 \\
\hline Peat & 0.7704 & 990.1 & 0.993 & 0.33136 & 428.5 & 0.990 \\
\hline Wheat straw & 0.4651 & 956.9 & 0.986 & 0.34909 & 346.4 & 0.981 \\
\hline Lucerne hay & 0.4023 & 925.1 & 0.979 & 0.30390 & 343.5 & 0.983 \\
\hline
\end{tabular}



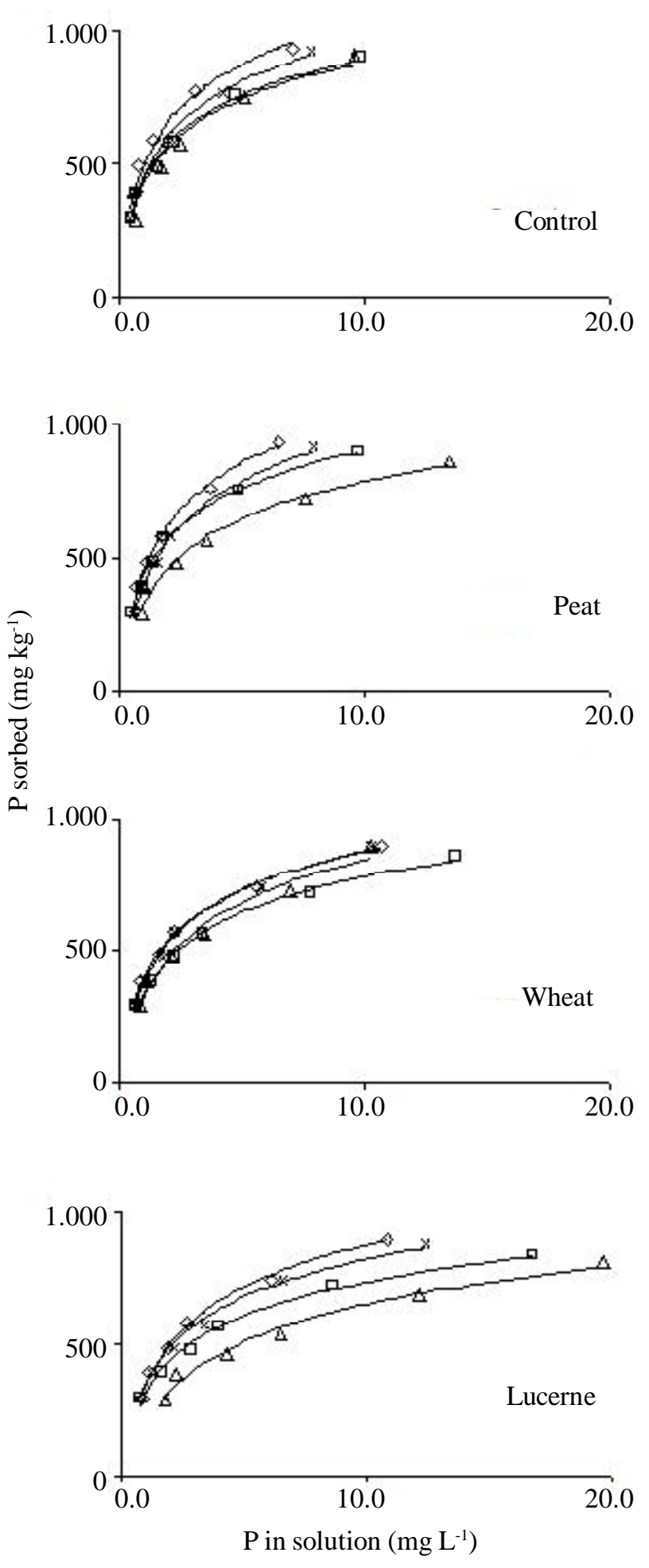

Figure 1. The effect of incubation time and organic matter sources on phosphate adsorption at $80 \mathrm{Mg} \mathrm{ha}^{-1}$ organic matter in 'Balkuling' Oxisol. $\diamond=$ three months, $\square=$ six months, $\triangle=$ nine months, and $X=$ twelve months incubation. Lines are a logarithmic trend of observations and a visual guide only.
Figure 1). This effect was observed despite the organic amendments becoming less effective at reducing phosphate adsorption with increasing time of incubation in soil. These conclusions are supported by the magnitude of the $x_{m}$ parameter of the Langmuir equation and $K_{F}$ of the Freundlich equation for every organic matter source throughout the incubation time (Table 1). The $x_{m}$ parameter was decreasing in value across incubations and increased again after nine month incubation.

The hypothesis that newly added OM would decrease phosphate adsorption, in the short-term, more than pre-existing SOM was not supported by the data in this experiment. A number of factors interacted to affect phosphate adsorption by soils in this highly complex the experiment, with no clear effect of OM addition, as described below.

Contradictory results were obtained on the effect of new SOM compared with existing SOM. Instead of dissolved phosphate concentrations increasing due to addition of new soil organic matter as predicted; these concentrations decreased indicating an increase in phosphate adsorption (Figure 3). The Langmuir equation, which fit the adsorption data from the first two subsets of data, was not suitable. A more complex equation (the BET isotherm equation) was needed in order to explain the sigmoidal curvature observed in phosphate adsorption for soil subjected to the treatments in this experimental subset (Hinz 2001).

Combustion of soil samples prior to new SOM application might have altered some physical and chemical characteristics of the soils which affect adsorption of phosphate. Even though Kang and Sajjapongse (1980) and Giovannini et al. (1988) found that a $450^{\circ} \mathrm{C}$ temperature had a minimal effect on other physical and chemical properties of soils such as porosity, textural class, and soil acidity, however, a temperature up to $160^{\circ} \mathrm{C}$ will almost certainly change the microbial community structure (Pietikainen et al. 2000). Moreover, heating up soil to around $300^{\circ} \mathrm{C}$ will reduce the amount of SOM, as well as CEC and exchangeable bivalent cations like $\mathrm{Ca}$ and $\mathrm{Mg}$ (Badia and Marti 2003; Brais et al. 2000; Forgeard and Frenot 1996). High temperature can change physical and chemical properties of the clays and oxides. According to Kang and Sajjapongse (1980), high temperature up to $500^{\circ} \mathrm{C}$ altered some soil chemical and physical properties. Giovannini et al. (1988) found, however, that temperatures of $460^{\circ} \mathrm{C}$ or more need to be attained to change the physical properties of the soil such as particle size distribution, plasticity, 

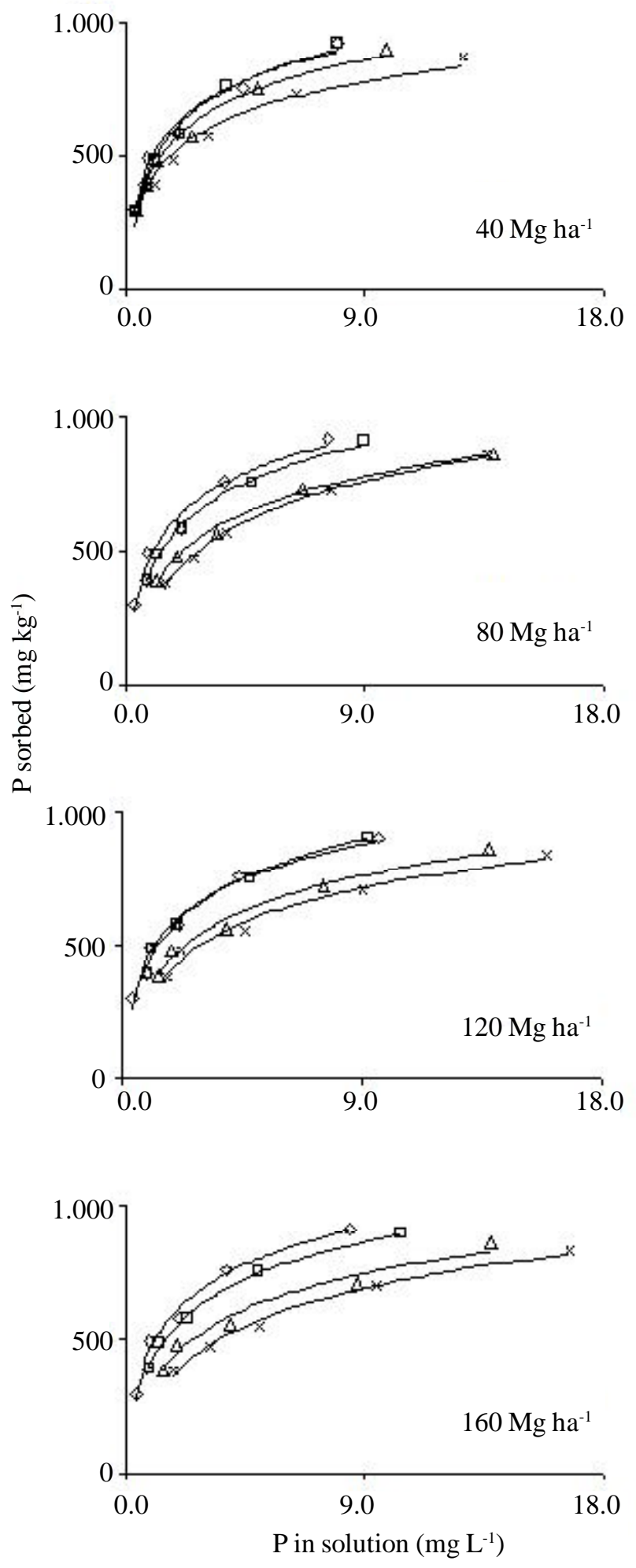

Figure 2. The effect of organic matter sources and their levels on phosphate adsorption at sixmonth incubation time in 'Balkuling' Oxisol. $\diamond=$ control, $\square=$ peat, $\triangle=$ wheat straw, and $\times=$ lucerne hay. Lines are a logarithmic trend of observations and are a visual guide only. and aggregate stability. In this experiment, heating soil to $450^{\circ} \mathrm{C}$ changed some parameters related to phosphate adsorption such as oxalate extractable-Al and $\mathrm{Fe}$ contents.

Subsurface (regolith) soil and the Ultisol appeared to change phosphate adsorption capacity more than the Oxisol (Figure 2). This may be because the increases in extractable- $\mathrm{Al}$ and $\mathrm{Fe}$ due to soil combustion were more pronounced in the subsurface soil ( $\mathrm{Al}_{\text {ox }}$ increased $\sim 10 \times, \mathrm{Fe}_{\text {ox }}$ increased $\sim 2.5 \times$ ) and the Ultisol $\left(\mathrm{Al}_{\text {ox }}\right.$ and $\mathrm{Fe}_{\text {ox }}$ increased $\sim 2.5 \times$ ) than in the Oxisol ( $\mathrm{Al}_{\text {ox }}$ increased $\sim 4 \times, \mathrm{Fe}_{\text {ox }}$ did not increase) due to dehydaration and dehydroxylation. This phenomenon was also observed by Gao et al. (2002) as they partially removed SOM from paddy soils. In line with these results, Su et al. (2001) and Singh and Gilkes (1991) also found a significant positive correlation between amorphous Fe-oxides and phosphate adsorption in soils. In soils with 1:1 lattice clays, phosphate adsorption is mainly attributed to the hydrous oxides of $\mathrm{Al}$ and $\mathrm{Fe}$, as well as occurring on the clay itself (Dubus and Becquer 2001; Sanyal et al. 1993).

The BET equation could explain the sigmoidal adsorption isotherms due to the above combustion. However, adsorption parameters in the original curvatures of adsorption (the Langmuir and Freundlich equation) appeared in negative slopes in the BET equation (Figure 2) to make numerical comparison impossible. Nevertheless, the decreasing trends of adsorption can be seen in Figure 3.

It is well known that the application of manure and organic materials reduces phosphate adsorption capacity in soils (Berton and Pratt 1997; Hundal et al. 1988). In order to see the importance of phosphate adsorption in releasing IP into soil solution we reviewed some BP data from the previous experiment (Yusran 2008). New SOM increased BP content, especially peat and lucerne hay in the Ultisol and the Oxisol (Yusran, 2008), despite increasing phosphate adsorption capacity due to the combustion of the soils (Figure 3) as also indicated by the increase of $K_{B E T}$ in Table 3. In other words, changes in phosphate adsorption appear to be less important as a BP release mechanism when soils are treated with $\mathrm{OM}$. According to Osiname et al. (2000) a sizable proportion of $\mathrm{P}$ released from OP mineralisation might be used to satisfy phosphate adsorption capacity of the soils. In applied practices, however, $\mathrm{P}$ mineralisation from $\mathrm{OM}$ should be accounted for when the adsorption isotherm technique is applied to 
Existing

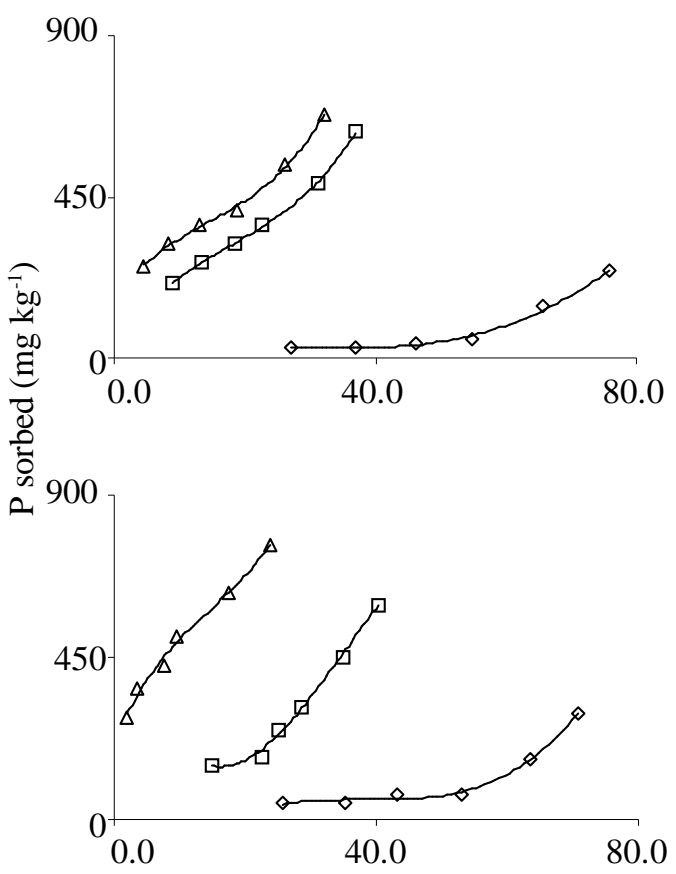

New
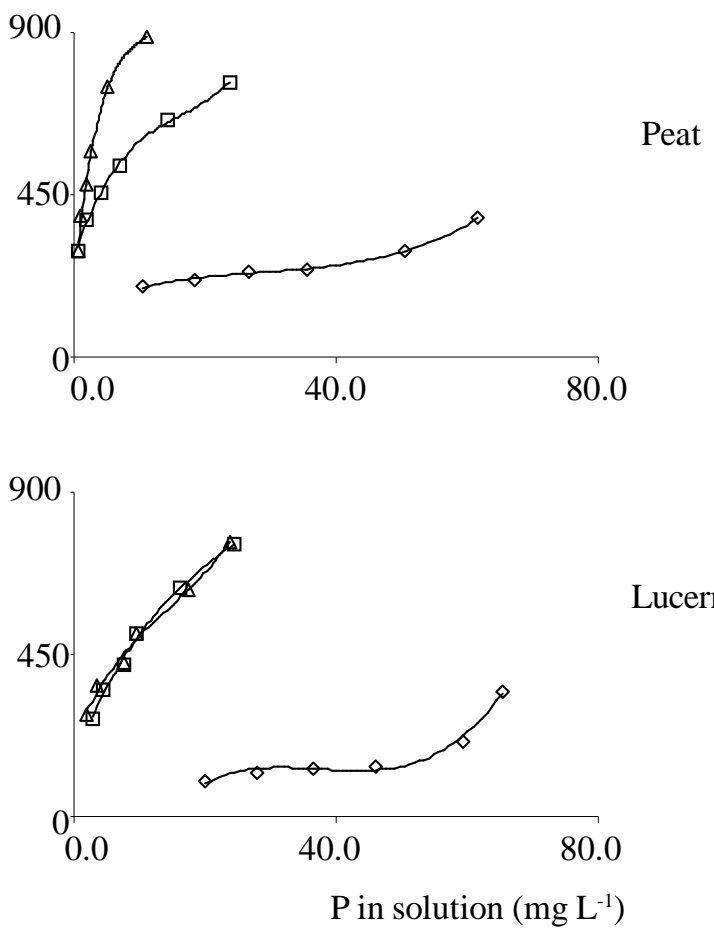

Figure 3. The effect of soils, existing and new soil organic matter on phosphate adsorption in peat and lucerne hay treatments at $\mathrm{Mg} \mathrm{ha}^{-1}$ and six-month incubation time. $\diamond=$ subsurface soil, $\square$ $=$ Ultisol, and $\triangle=$ Oxisol. Lines are polynomial trend for observations and are a visual guide only.

soils that have been amended with organic materials (Berton and Pratt 1997). In this experiment, although combustion plus treatment of soils with new SOM increased phosphate adsorption capacity, the BP release to soil solution showed no sign of decreasing. Contributions from incomplete oxidation of organic$\mathrm{P}$ during combustion and the changes in acid solubility of soil inorganic-P (Anderson 1960; Condron et al. 1990; Williams et al. 1970) as a result of combustion might also have occurred in soil samples.

Increasing the level of $\mathrm{OM}$ in all treatments (i.e. peat, wheat straw, and lucerne hay) did not show the same trend in phosphate adsorption for all OM sources. Wheat straw and lucerne hay, according to their values of $K_{L}$ in Table 2, consistently decreased phosphate sorption as the level of their applications increased. Peat, however, showed almost similar $K_{L}$ values as the level of application increased. In other words, increasing level up to $180 \mathrm{Mg} \mathrm{ha}^{-1}$ was ineffective for the purpose of decreasing phosphate adsorption in an Oxisol, when peat was applied.

Decreasing phosphate adsorption due to the increasing level of organic matter addition may also be explained as a consequence of $\mathrm{P}$ content in their biomass. When phosphate is released during decomposition of organic matter, it is then rapidly adsorbed onto sorption sites. Therefore, more adsorbed $\mathrm{P}$ is present before the equilibration by $\mathrm{CaCl}_{2}$ solution (Haynes and Mokolobate 2001; Iyamuremye and Dick 1996; Li et al. 1990). As a result, there is less phosphate adsorption capacity of the soil with respect to subsequently added phosphate.

Different types of OM had different effects on phosphate adsorption. Lucerne hay decreased phosphate adsorption more than wheat straw and wheat straw decreased phosphate adsorption more than peat (Table 1). Comparable values in Table 1 (row six months) and Table 2 (row $80 \mathrm{Mg} \mathrm{ha}^{-1}$ ) appeared to be slightly different due to different sub samplings. However, declining trends in parameter $K_{L}, x_{m}, b$ and $K_{F}$ were similar to the effect of different OM sources. At the same time, increasing the amount of OM application also reduced phosphate adsorption more, indicating similar trend of declining phosphate adsorption capacity. Even at $180 \mathrm{Mg} \mathrm{ha}^{-1}$, the order of effect was peat $<$ wheat straw $<$ lucerne hay. The 
Table 3. The effect of soil organic matter type (existing and new) and soil types (subsurface soil, Ultisol, and Oxisol) on phosphate adsorption parameters based on fitting data to the Brunauer-EmmettTeller equation.

\begin{tabular}{|c|c|c|c|c|c|c|}
\hline \multirow{3}{*}{$\begin{array}{l}\text { Organic matter } \\
\text { source }\end{array}$} & \multicolumn{6}{|c|}{ Soil organic matter } \\
\hline & \multicolumn{2}{|c|}{ Existing } & & \multicolumn{2}{|c|}{ New } & \multirow[b]{2}{*}{$\mathrm{R}^{2}$} \\
\hline & $\mathrm{X}_{\mathrm{m}}$ & $\mathrm{K}_{\mathrm{BET}}$ & $\overline{\mathrm{R}^{2}}$ & $\mathrm{x}_{\mathrm{m}}$ & $\mathrm{K}_{\mathrm{BET}}$ & \\
\hline \multicolumn{7}{|c|}{ Subsurface soil } \\
\hline Peat & -70 & -8.4 & 0.543 & 408 & 49.0 & 0.885 \\
\hline Lucerne hay & -132 & -7.6 & 0.467 & 1111 & 4.5 & 0.047 \\
\hline \multicolumn{7}{|c|}{ Ultisol } \\
\hline Peat & 1351 & 18.5 & 0.666 & 767 & 34.3 & 0.986 \\
\hline Lucerne hay & -625 & -16.0 & 0.524 & 991 & 12.1 & 0.983 \\
\hline \multicolumn{7}{|c|}{ Oxisol } \\
\hline Peat & 820 & 61.0 & 0.858 & 998 & 501.0 & 0.995 \\
\hline Lucerne hay & 893 & 56.0 & 0.739 & 903 & 158.1 & 0.959 \\
\hline
\end{tabular}

Table 4. Correlation between inorganic phosphorus, dissolved organic carbon, extractable aluminium, and extractable iron in uncombusted soils treated with peat and lucerne hay treatments. Only significant correlations are presented.

\begin{tabular}{llllllll}
\hline & \multicolumn{3}{c}{ Existing SOM + peat } & & \multicolumn{3}{c}{ Existing SOM + lucerne hay } \\
\cline { 2 - 3 } & $\mathrm{BP}$ & $\mathrm{DOC}$ & $\mathrm{Al}$ & & $\mathrm{BP}$ & $\mathrm{DOC}$ & $\mathrm{Al}$ \\
\hline $\mathrm{DOC}$ & & & & & $0.63^{* *}$ \\
$\mathrm{Al}$ & $-0.83^{* *}$ & & & $-0.72^{* *}$ & $-0.69^{* *}$ & \\
$\mathrm{Fe}$ & $-0.64^{* *}$ & $-0.44^{*}$ & $0.44^{*}$ & & $-0.61^{* *}$ & $-0.82^{* *}$ & $0.56^{* *}$ \\
\hline
\end{tabular}

$\mathrm{SOM}=$ soil organic matter, $\mathrm{DOC}=$ dissolved organic $-\mathrm{C}, \mathrm{BP}=$ bicarbonate-P. $*$ represents a significant $(\mathrm{p} \leq 0.05)$ and $* *$ a highly significant $(\mathrm{p} \leq 0.01)$ correlation.

fact that peat increased BP content in soils (Yusran et al. 2002; Yusran 2008) higher than wheat straw application again suggests that phosphate adsorption was not the dominant factor affecting BP release after peat addition. Though peat has lower $\mathrm{P}$ content than wheat straw (Yusran 2008), it could provide more BP if it is applied to soil. Peat probably could facilitate OP transformation to IP better than wheat straw by other mechanisms, except decreasing phosphate adsorption.

\section{CONCLUSIONS}

Organic matter addition could reduce phosphate adsorption and the effect could last up to nine months after application. Lucerne hay was more effective than peat and wheat straw addition in reducing phosphate adsorption capacity. Langmuir equation fitted better than Freundlich in describing phosphate adsorption in this experiment.

Soil combustion in new SOM addition treatments increased phosphate adsorption capacity, especially in the Oxisol and Ultisol. At the same time, only the BET equation could describe the sigmoidal effect of treatments on phosphate adsorption. Consequently, comparing the effect of existing and new SOM treatment by comparing equation parameters was impossible.

The new SOM addition released more BP into soil solution. The experiment revealed the reduction of phosphate adsorption occurred during the first year of OM applications and long term release of BP in soil contributed to mineralisation, $\mathrm{P}$ hydrolysis, or $\mathrm{P}$ transformation. 


\section{ACKNOWLEDGMENT}

This research was supported by an ADS (Australian Development Scholarship) funded by AusAID. Supervision and guidance from Andrew W. Rate and Prof. Lyn K. Abbott were greatly appreciated.

\section{REFERENCES}

Afif E, V Barron and J Torrent. 1995. Organic matter delays but does not prevent phosphate sorption by cerrado soils from Brazil. Soil Sci Soc Am Proc 159: 207-211.

Anderson G. 1960. Other organic phosphorus compounds. In Soil Component Ed: JE Geiseking. SpringerVerlag, New York.

Badia D and C Marti. 2003. Plant ash and heat intensity effects on chemical and physical properties of two contrasting soils. Arid Land Res Manag 17: 23-41.

Barrow NJ. 1978. The description of phosphate adsorption curves. J Soil Sci 29: 447-462.

Berton RS and PF Pratt. 1997. Evaluation of phosphorus requirement by the sorption isotherm technique in soils amended with organic materials. Revista Brasileira de Ciencia do Solo 21: 199-206.

Brais S, P David and R Ouimet. 2000. Impacts of wild fire severity and salvage harvesting on the nutrient balance of jack pine and black spruce boreal stands. Forest Ecol Manag 137: 231-243.

Burau RG and RJ Zasoski. 2002. Soil and Water Chemistry. Course Notes and Graphical Materials. University of California Davis, California.

Coakes SJ. 2001. SPSS: Analysis without Anguish. John Wiley and Sons, Brisbane.

Cobo JG, E Barrios, DCL Kass and RJ Thomas. 2002. Decomposition and nutrient release by green manures in a tropical hillside agroecosystem. Plant Soil 240: 331-342.

Condron LM, JO Moir, H Tiessen and JWB Stewart. 1990. Critical evaluation of methods for determining total organic phosphorus in tropical soils. Soil Sci Soc Am J 54: 1261-1266.

Dubus IG and T Becquer. 2001. Phosphorus sorption and desorption in oxide-rich Ferralsols of New Caledonia. Aust J Soil Res 39: 403-414.

Erich MS, CB Fitzgerald and GA Porter. 2002. The effect of organic amendments on phosphorus chemistry in a potato cropping system. Agric Ecos Envir 88: 7988.

Forgeard F and Y Frenot. 1996. Effects of burning on heathland soil chemical properties: an experimental study on the effect of heating and ash deposits. J App Ecol 33: 803-811.
Gao M, B Zhou, C Wei and F Che. 2002. Characteristics of phosphorous adsorption and desorption by organomineral colloidal complexes of purple paddy soils. Pedosphere 12: 257-264.

Giles CH, D Smith and A Huitson. 1974. A general treatment and calssification of the solute adsorption isotherm. I: Theoritical. J Col Interf Sci 47: 755-765.

Giovannini G, S Lucchesi and M Giachetti. 1988. Effect of heating on some physical and chemical parameters related to soil aggregation and erodibility. Soil Sci 146: $255-261$.

Haynes RJ and R Naidu. 1998. Influence of lime, fertilizer and manure applications on soil organic matter content and soil physical conditions: A review. Nut Cyc Agroecos 51: 123-137.

Haynes RJ and MS Mokolobate. 2001. Amelioration of Al toxicity and $\mathrm{P}$ deficiency in acid soils by additions of organic residues: a critical review of the phenomenon and the mechanisms involved. Nut Cyc Agroecos 59: 47-63.

Hinz C. 2001. Description of sorption data with isotherm equations. Geoderma 99: 225-243.

Hue NV, H Ikawa, and JA Silva. 1994. Increasing pantavailable phosphorus in an Ultisol with a yard-waste compost. Comm. Soil Sci Plant Anal 25: 3291-3303.

Hundal HS, CR Biswas and AC Vig. 1988. Phosphorus sorption characteristics of flooded soil amended with manures. Trop Agric 65: 185-187.

Iyamuremye F and RP Dick. 1996. Organic amendments and phosphorus sorption by soils. Advances in Agronomy 56:139-185.

Kang BT and A Sajjapongse. 1980. Effect of heating on properties of some soils from southern Nigeria and growth of rice. Plant Soil 55: 85-95.

Kwabiah AB, CA Palm, NC Stoskopf and RPVoroney. 2003. Response of soil microbial biomass dynamics to quality of plant materials with emphasis on $\mathrm{P}$ availability. Soil Biol Biochem 35: 207-216.

Li GC, RL Mahler and DO Everson. 1990. Effects of plant residues and environmental factors on phosphorus availability is soils. Comm Soil Sci Plant Anal 21: 471-491.

Lupwayi NZ, GW Clayton, KN Harker, TK Turkington, WA Rice and AM Johnston. 2003. Impact of crop residue type on phosphorus release. Better Crops with Plant Food 87: 4-5.

Morel C, H Tiessen and JWB Stewart. 1996. Correction for P-sorption in the measurement of soil microbial biomass $\mathrm{P}$ by $\mathrm{CHCl}_{3}$ fumigation. Soil Biol Biochem 28: 1699-1706.

Naidu R, RS Kookana, ME Sumner, RD Harter, and KG Tiller. 1997. Cadmium sorption and transport in variable charge soils: a review. J Environ Qual 26: 602-617. 


\section{FH Yusran: Organic Matter Addition on Phosphate Adsorption and Soil Organic Carbon}

Ohno T and BS Crannel. 1996. Green and animal manurederived organic matter effects on phosphorus sorption. J Envir Qual 25: 1137-1143.

Osiname OA, F Meppe and L Everett. 2000. Response of maize (Zea mays) to phosphorus application on basaltic soils in Northwestern Cameroon. Nut Cyc Agroecos 56: 209-217.

Payne RW, PW Lane, AE Ainsley, KE Bicknell, PGN Digby, SA Harding, PK Leech, HR Simpson, AD Todd, PJ Verrier and RP White. 1987. Genstat 5 Reference Manual. Oxford University Press, Oxford.

Pietikainen J, R Hiukka and HFritze. 2000. Does short-term heating of forest humus change its properties as a substrate for microbes. Soil Biol Biochem 32: 277288.

Rayment GE and FR Higginson. 1992. Australian Laboratory Handbook of Soil and Water Chemical Methods. Inkata Press, Melbourne.

Reddy DD, AS Rao and M Singh. 2001. Crop residue addition effects on myriad forms and sorption of phosphorus in a Vertisol. Biores Tech 80: 93-99.

Sanyal SK, SK De Datta and PY Chan. 1993. Phosphate sorption-desorption behaviour of some acidic soil of south-east Asia. Soil Sci Soc Am J 42: 432-436.
Singh B and RJ Gilkes. 1991. Phosphorus sorption in relation to soil properties for the major soil types of Southwestern Australia. Aust J Soil Res 29: 603-618.

Singh BB and JP Jones. 1976. Phosphorus sorption and desorption characterisitcs of soil as affected by organic residues. Soil Sci Soc Am J 40: 389-394.

Su L, Y Zhang and X Lin. 2001. Changes of iron forms and phosphorus adsorption-desorption in flooded-dried paddy soils. Plant Nut Fert Sci 7: 410-415.

Williams JDH, JK Syers, TW Walker and RW Rex. 1970. A comparison of methods for determination of soil organic phosphorus. Soil Sci 110: 13-18.

Yusran FH, AW Rate and LK Abbott. 2002. Transformation of organic matter in an Oxisol. In 17th World Congress of Soil Science, Bangkok.

Yusran FH, AW Rate and LK Abbott. 2005. Transformation of organic matter in an Oxisol in response to the application of various sources of organic carbon. Agroscientiae 12: 123-135.

Yusran FH. 2008. Existing versus added organic matter in relation to phosphorus availability on lateritic soils. J Trop Soils 13: 23-34. 